\title{
Sonographic Diagnosis of Papillary Thyroid Carcinoma
}

\author{
Mohi Al-Tamami ${ }^{a}$ Hanaa Al-Khawari ${ }^{a}$ Hilal Al-Sayer ${ }^{b}$ \\ Taleb Jumaab \\ Departments of a Clinical Radiology and bSurgery, Al-Amiri Hospital, Kuwait
}

\section{Key Words}

Papillary thyroid carcinoma .

Ultrasonography

\begin{abstract}
Objective: To assess the value of ultrasonography (US) in reliably differentiating benign from malignant thyroid nodules, and in defining the malignant nature and the histotype of papillary thyroid carcinomas (PTC). Methods: A high-resolution real-time US system with a 7.5-MHz linear probe was used. The sonographic features of 39 histopathologically proven PTC cases were retrospectively reviewed and compared with the US features of 52 benign thyroid nodules (BTN). The US identification of PTC malignancy was based on the simultaneous presence of multiple US features seen exclusively in PTC and not in BTN. Results: Based on the simultaneous presence of exclusive malignant US
\end{abstract}

\begin{tabular}{ll}
\hline KARGER & (c) 2000 S. Karger AG, Basel \\
Fax +4161306 1234 $3411-7571 / 00 / 0091-0025 \$ 17.50 / 0$ \\
$\begin{array}{l}\text { E-Mail karger@karger.ch } \\
\text { www.karger.com }\end{array}$ & $\begin{array}{l}\text { Accessible online at: } \\
\text { www.karger.com/journals/mpp }\end{array}$
\end{tabular}

features seen in PTC but not in BTN, identification of the malignant nature of PTC was certain in $74 \%$ of the cases and less certain in $8 \%$ of the cases. In a third group, $15 \%$ of the cases showed predominantly benign US features, while 1 patient (3\%) was operated as a case of multinodular goiter and diagnosed histologically as having occult PTC. No malignant features were seen by US and it was not associated with metastasis. US identification of the histological type of PTC was based on the finding that a thyroid lesion presenting as a predominant cyst with a punctately calcified endoluminal projecting solid mural nodule was an exclusively specific feature of cystic primary PTC. Both, totally cystic and microcalcified predominantly cystic metastatic lymph nodes were also characteristically seen in metastatic PTC. Accordingly, the histotype of PTC was only identified in its cystic form, whether it was primary $(13 \%)$ or metastatic (31\%). Both constituted $44 \%$ of

\footnotetext{
Dr. Mohi Al-Tamami MD, PhD

Department of Clinical Radiology, Al-Amiri Hospital, PO Box 4077 13041 Safat (Kuwait)

Tel. +965 2467498, Fax +965 2447584

E-Mail h.alkhawari@hsc.kuniv.edu.kw
} 
the 39 PTC cases. Conclusion: High-resolution real-time ultrasonography was found to be a useful first line diagnostic modality of PTC. It was reliable in differentiating benign from malignant thyroid nodules and in identifying the histotype of PTC in cases with cystic metastasis or where the primary or the metastatic nodule is cystic with microcalcified projecting solid mural nodule. Fine needle aspiration biopsy is to be resorted to, mainly in equivocal cases.

Copyright $(\subset 2000$ S. Karger AG, Basel

\section{Introduction}

High-resolution ultrasonography (US) is the most sensitive modality for identifying very small nodular thyroid lesions [1-5]. Although US differentiation between benign and malignant thyroid nodules has been unreliable $[5,6]$, recent technological advances in imaging systems [4] have greatly improved its sensitivity in the detection and differentiation of thyroid nodules. The purpose of the present study is to determine whether US examination can reliably differentiate between a benign and a malignant thyroid nodule and to assess the nature of its malignancy especially in papillary thyroid carcinoma (PTC), which is the most common type of thyroid malignancy $[4,5]$.

\section{Patients and Methods}

The US features of 39 histologically proven cases of PTC ( 37 nodular and 2 occult cases) were retrospectively reviewed. US examination was performed using a real-time high-resolution US scanner with a $7.5-\mathrm{MHz}$ linear probe. The thyroid gland was examined in multiple planes with US to detect the lesions and characterize their features. US examination was extended to involve the whole neck to facilitate the detection of enlarged lymph nodes and other relevant findings.
The sonographic features that were reviewed for each thyroid nodule were: (1) nodular size (maximum US diameter); (2) physical characteristics (solid/cystic/ mixed or complex); (3) nodular margin (well defined/ poorly defined); (4) echolucent halo (present or absent; its echo features); (5) echodensity of solid nodules in relation to normal thyroid parenchyma (hypoechogenic/isoechogenic/hyperechogenic); (6) internal echo pattern of solid nodules (homogeneous/heterogeneous/ cystic degenerative changes); (7) echo features of cystic nodules (total cyst/predominant cyst with endoluminal solid components); (8) nodular calcification (microcalcification/coarse calcification/shell-type calcification); (9) distal acoustic intensity (enhanced/reduced/no change); (10) malignant spread (direct/lymphatic/hematogenic).

\section{Results}

Many US features were common to both PTC and benign thyroid nodules (BTN). Some features were either more prevalent in PTC or in BTN, while other features were seen either exclusively in PTC or in BTN (table 1). The exclusive US features seen in PTC that were considered as indicators of malignancy were: (1) poorly defined nodular margins, (2) thick irregular echolucent halo, (3) heterogeneous solid internal echo pattern, (4) cystic lesion with punctately calcified endoluminal projecting solid mural nodule, (5) microcalcification, as well as (6) evidence of extraglandular malignant spread. Figures 1 and 2 illustrate exclusive features of primary and metastatic PTC whereas figure 3 illustrates features of BTN.

The US presentation of the 39 PTC cases was categorized into four groups (table 2). In the first group of $29(74 \%)$ cases, multiple (more than one) exclusively malignant features were seen in each case. In the second group of $3(8 \%)$ cases, only one US feature was exclusively malignant, one predominantly malignant, and two predominantly benign. In the third group of $6(15 \%)$ cases, US pre- 
Table 1. US features of discrete nodular PTC and BTN

\begin{tabular}{|c|c|c|c|}
\hline No. & Description & $\begin{array}{l}\text { Percent } \\
\text { of } 37 \text { PTC }\end{array}$ & $\begin{array}{l}\text { Percent } \\
\text { of } 52 \text { BTN }\end{array}$ \\
\hline \multicolumn{4}{|c|}{ Predominantly PTC features } \\
\hline 1 & Totally solid nodule & 75 & 46 \\
\hline 2 & Hypoechogenic solid nodule & 61 & 17 \\
\hline 3 & No distal acoustic enhancement & 67 & 19 \\
\hline 4 & $\begin{array}{l}\text { Cystic with endoluminal noncalcified fixed projecting } \\
\text { mural nodule }\end{array}$ & 6 & 2 \\
\hline \multicolumn{4}{|c|}{ Exclusively PTC US features $^{1}$} \\
\hline 1 & Poorly defined nodular margin & 81 & \\
\hline 2 & Thick irregular echolucent halo & 27 & \\
\hline 3 & Heterogeneous solid nodule & 58 & \\
\hline 4 & $\begin{array}{l}\text { Presentation as a predominant cyst with punctately } \\
\text { calcified endoluminal fixed projecting mural nodule }\end{array}$ & 14 & \\
\hline 5 & Microcalcification & 38 & \\
\hline 6 & US evidence of extraglandular malignant spread & 41 & \\
\hline \multicolumn{4}{|c|}{ Predominantly BTN US features } \\
\hline 1 & Well-defined nodular margin & 16 & 100 \\
\hline 2 & Cystic nodule & 19 & 27 \\
\hline 3 & Cystically degenerated solid nodule & 5 & 27 \\
\hline 4 & Isoechogenic solid nodule & 14 & 21 \\
\hline 5 & Homogeneous solid nodule & 17 & 46 \\
\hline 6 & Echolucent halo & 24 & 48 \\
\hline 7 & Thin regular halo & 3 & 48 \\
\hline 8 & Distal acoustic enhancement & 30 & 81 \\
\hline 9 & Coarse nodular calcification & 3 & 15 \\
\hline \multicolumn{4}{|c|}{ Exclusively BTN features } \\
\hline 1 & Hyperechogenic solid nodule & & 8 \\
\hline $2 \mathrm{a}$ & Total cyst ... clear & & 10 \\
\hline $2 b$ & Total cyst ... with fine mobile layered echoes & & 8 \\
\hline 3 & Composite cyst with irregular endoluminal solid components & & 8 \\
\hline 4 & Thin shell type nodular calcification & & 8 \\
\hline 1 & $\begin{array}{l}\text { All values rounded to nearest integer. } \\
\text { JS features exclusively seen in PTC and not in BTN. }\end{array}$ & & \\
\hline
\end{tabular}

sentation was predominantly benign, and in 1 (3\%) occult PTC case which was not associated with metastasis, and diagnosed histopathologically in a patient operated for multinodular goiter, US examination was totally negative for malignant features.

Sonographic Diagnosis of Papillary Thyroid Carcinoma
The majority (76\%) of nodular PTC were totally solid, while cystic and cystically degenerated solid nodules accounted for 19 and 5\%, respectively. All cystic primary PTC (7 cases) were in the form of a predominant cyst with one or more solid endoluminal projecting mural nodules. Five of these were punctately cal- 


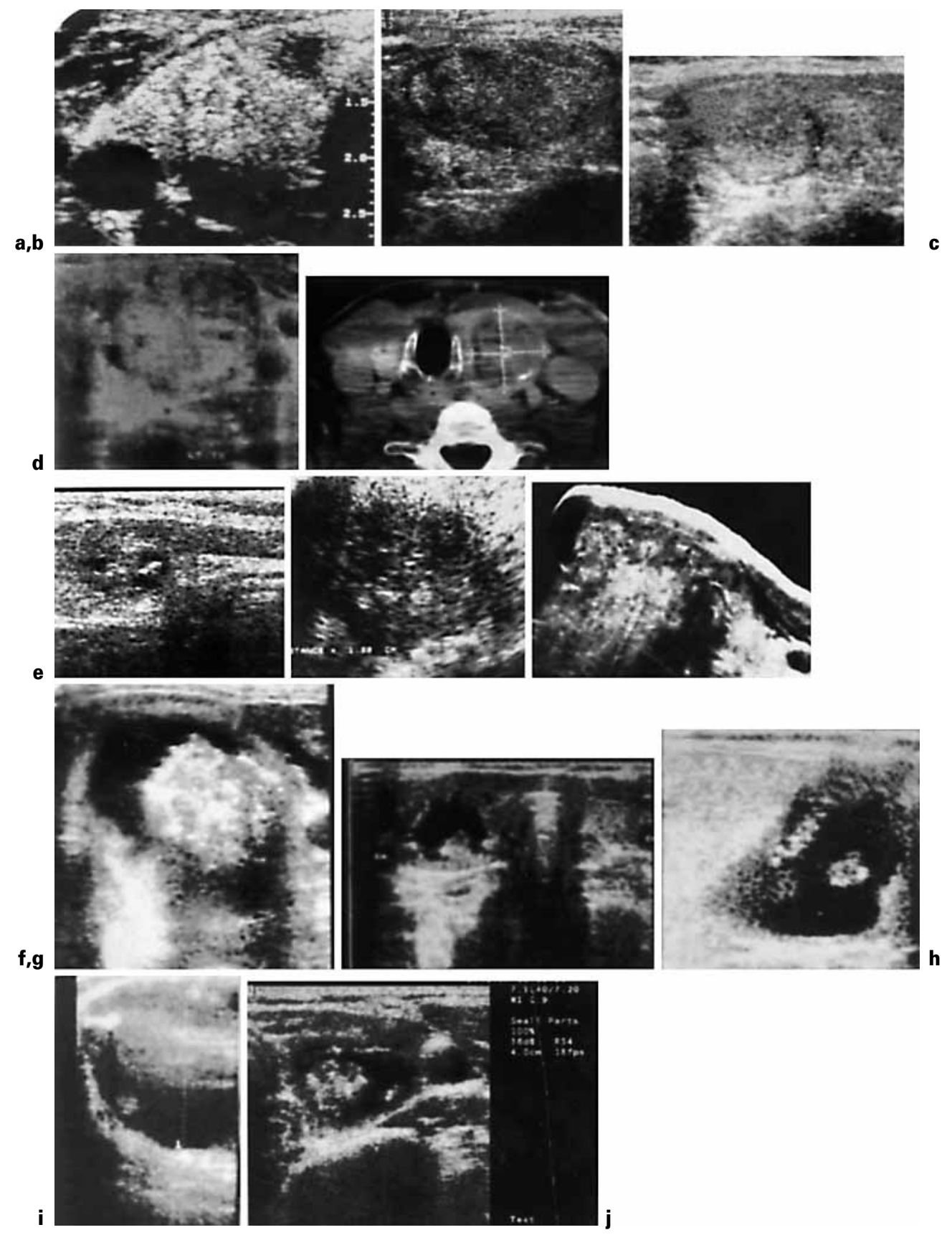

Fig. 1. PTC. a-e Solid primary PTC illustrating exclusively malignant US features. a Irregular ill-defined nodular margin. b Heterogeneous solid internal echo pattern. c, d Thick irregular translucent halo (CT of $\mathbf{d}$ showed focal punctate marginal calcification not seen by US). e Three cases each showing: irregular ill- defined margin, heterogeneous solid internal echo pattern and nodular microcalcifications. $\mathbf{f - i}$ Cystic primary PTC illustrating exclusively malignant US features: Cystic nodules with one or more punctately calcified endoluminal projecting solid components. 


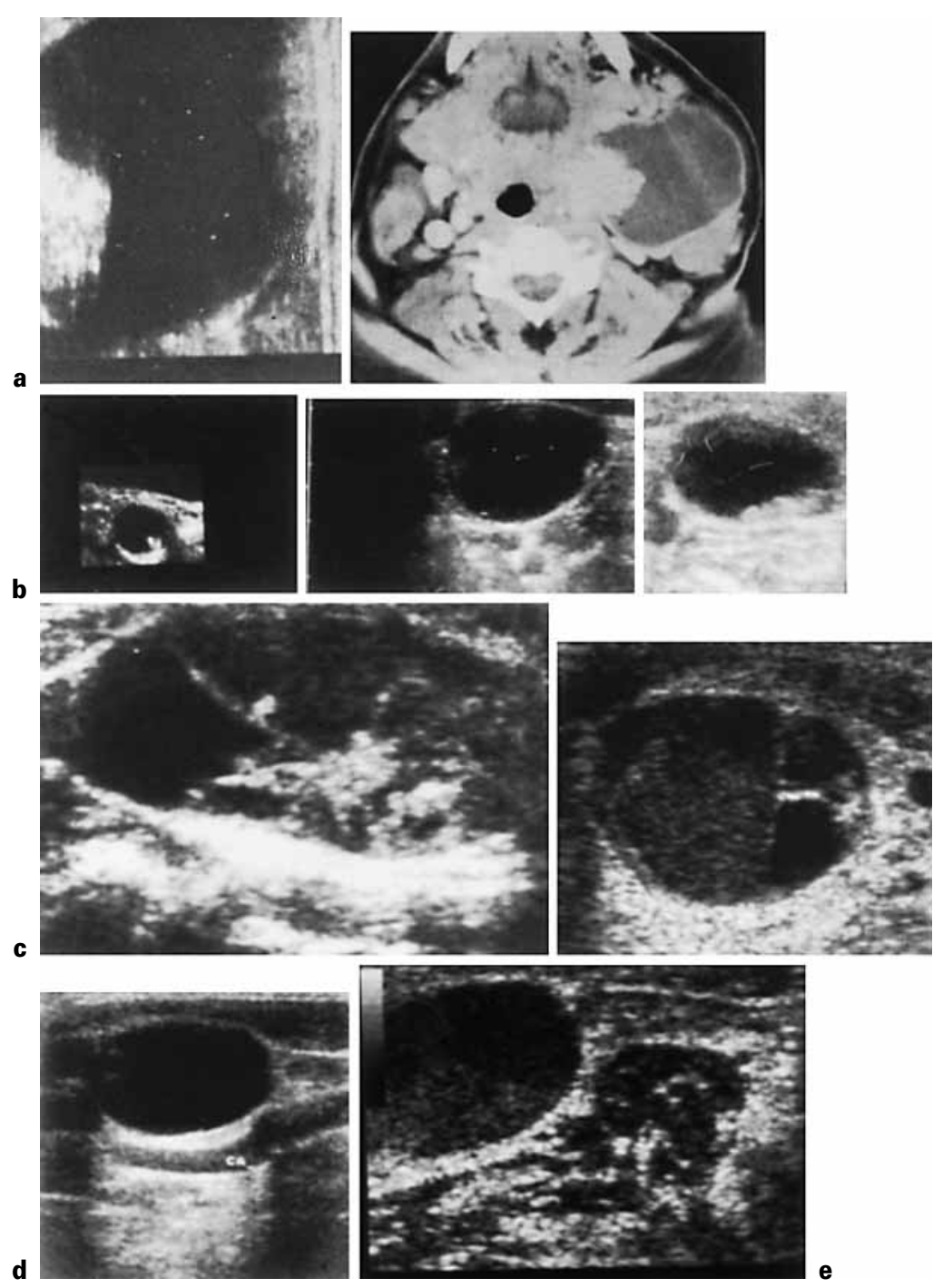

Fig. 2. Metastatic PTC in cervical lymph nodes illustrating US features characteristic of PTC metastasis. a Cystic lymph node with punctately calcified projecting solid mural nodule (US and CT). b Three cystic nodes similar to $\mathbf{a}$ with calcified projecting mural nod-

cified and there was no calcification detected in the other 2 cases (fig. $1 \mathrm{f}-\mathrm{j}$ ).

On the other hand, $46 \%$ of BTN were totally solid, while cystic and cystically degenerated solid nodules collectively accounted for

Sonographic Diagnosis of Papillary Thyroid Carcinoma ules of various sizes. c Two cystic lymph nodes with punctately calcified endoluminal septations. d, e Two totally cystic echofree lymph nodes (in e microcalcified solid metastatic node is seen adjacent to the cystic node).

$54 \%$. Of the 14 cystic BTN, 5 were totally cystic and echofree, 4 were totally cystic with layered mobile echoes, and 4 were composite cysts with noncalcified irregular solid components (fig. 3). One of the cystic BTN was pre-

Med Principles Pract 2000;9:25-34 29 
Fig. 3. $B T N$. a-f BTN illustrating exclusively benign (EB) US features. a Homogeneous internal solid echo pattern. b Hyperechogenic nodule (partially degenerated). c Degenerative cyst with irregular solid components. d Totally cystic nodules with layered mobile echoes. e Echofree totally cystically degenerated nodule with coarse-focal wall calcification. f Shell-type nodular calcifications.

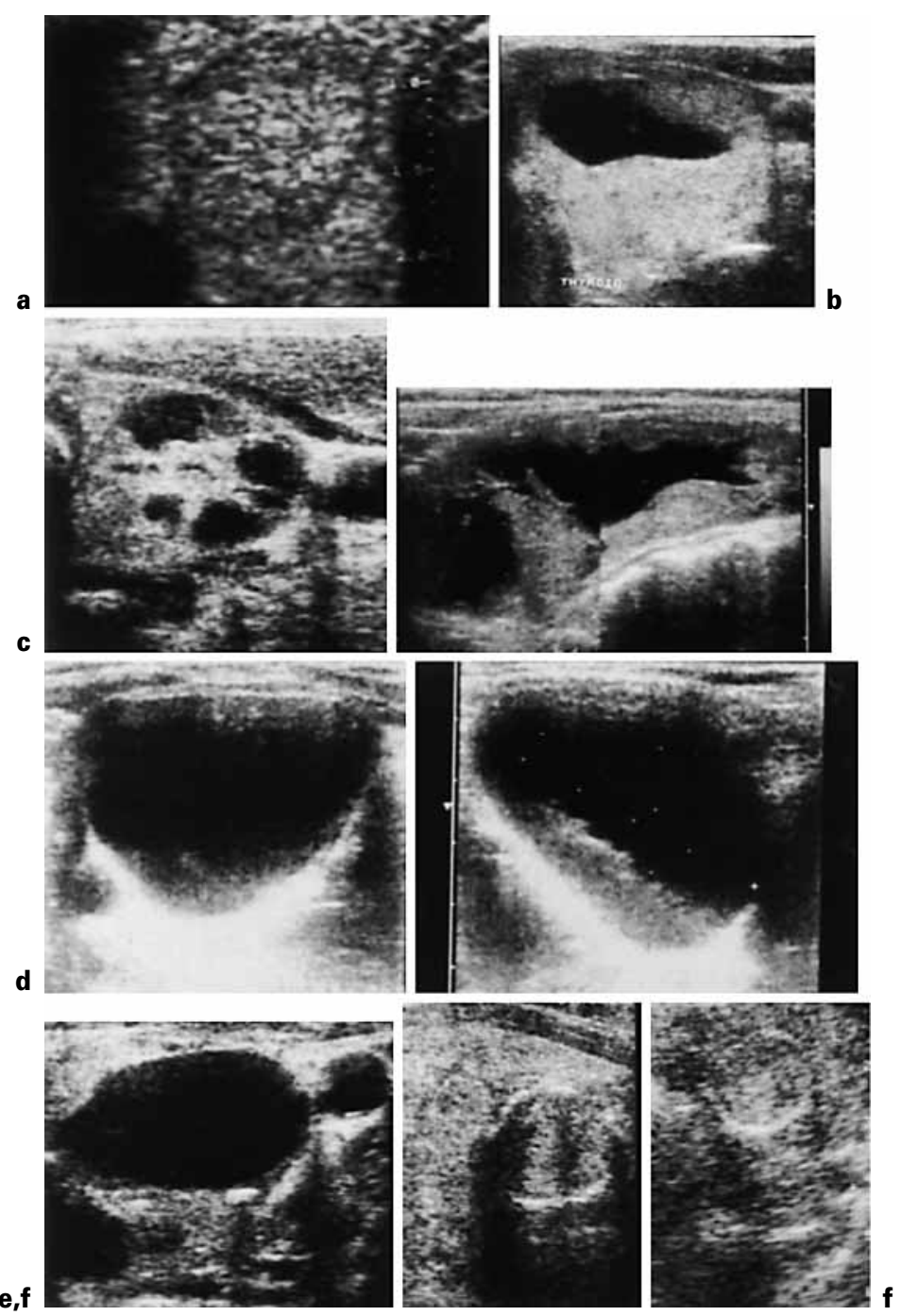

dominantly cystic with an endoluminal projecting solid mural nodule which showed no calcification.

\section{Metastatic Spread}

Of the 39 PTC cases, 15 (38\%) cases were metastatic of which 1 was occult PTC presenting with metastasis in the cervical lymph nodes. The most frequent mode of metastatic spread demonstrated by histological examina- tion was via the lymphatics, which occurred in all 15 cases. In addition to the lymphatic spread, 5 cases had direct spread and 1 case hematogenic spread. Metastatic PTC in the lymph nodes was more frequently cystic than primary. In 12 cases, the metastatic lymph nodes were all cystic with some being totally cystic and some composite with microcalcified endoluminal solid components (fig. 2). In the remaining 3 patients, these cystic meta-
30

Med Principles Pract 2000;9:25-34
Al-Tamami/Al-Khawari/Al-Sayer/ Jumaa 
Table 2. Group categories of US presentation of 39 PTC cases

\begin{tabular}{|c|c|c|c|c|}
\hline \multirow[t]{2}{*}{ Group category } & \multicolumn{2}{|c|}{ Cases } & \multicolumn{2}{|c|}{ US features } \\
\hline & $\mathrm{n}$ & $\%{ }^{\mathrm{a}}$ & & \\
\hline Exclusively malignant (EM) & 29 & 74 & $\begin{array}{r}\text { multipl } \\
\text { multipl } \\
\text { lym } \\
\text { lympha }\end{array}$ & $\begin{array}{l}\text { IF in each of } 13 \text { cases } \\
\mathrm{IF}+\text { metastasis (direct and/or } \\
\text { c) in each of } 13 \text { cases } \\
\text { etastasis in } 3\end{array}$ \\
\hline Predominantly malignant (PM) & 3 & 8 & $\begin{array}{l}1 \mathrm{EMF} \\
1 \mathrm{PMF} \\
2 \mathrm{PBF}\end{array}$ & in each case \\
\hline Predominantly benign (PB) & 6 & 15 & $\begin{array}{l}1 \mathrm{EBF} \\
2 \mathrm{PBF} \\
1 \mathrm{PMF}\end{array}$ & in each case \\
\hline Negative US presentation & 1 & 3 & occult $\mathrm{F}$ & vith no metastasis \\
\hline
\end{tabular}

a Rounded to nearest integer.

b More than one.

$\mathrm{EMF}=$ Exclusively malignant feature; $\mathrm{PMF}=$ predominantly malignant feature; $\mathrm{EBF}=$ exclusively benign feature; $\mathrm{PBF}=$ predominantly benign feature.

Table 3. Variation of incidence of extraglandular metastasis with US features of 37 nodular PTC

\begin{tabular}{|c|c|c|c|c|c|c|}
\hline \multirow[t]{2}{*}{ Nodular form } & \multicolumn{3}{|c|}{ Cases } & \multicolumn{3}{|c|}{ Echo features of PTC nodules } \\
\hline & total & $\mathrm{n}$ & $\% 0^{\mathrm{a}}$ & & total & $\mathrm{n}$ \\
\hline \multirow[t]{9}{*}{ Totally solid } & 27 & 12 & 44 & echogenicity & & \\
\hline & & & & hypoechogenic (PM) & 23 & 10 \\
\hline & & & & isoechogenic $(\mathrm{PB})$ & 4 & 2 \\
\hline & & & & margin & & \\
\hline & & & & well-defined (PB) & 6 & 2 \\
\hline & & & & ill-defined (EM) & 21 & 10 \\
\hline & & & & echo texture & & \\
\hline & & & & homogeneous (PM) & 7 & 2 \\
\hline & & & & heterogeneous (EM) & 20 & 10 \\
\hline $\begin{array}{l}\text { Composite } \\
\text { cystic/solid }\end{array}$ & 10 & 2 & 20 & & & \\
\hline
\end{tabular}

Total $=$ Total number of cases; $\mathrm{n}=$ number of cases with metastasis; $\mathrm{EM}=$ exclusively malignant; $\mathrm{PM}=$ predominantly malignant; $\mathrm{PB}$ = predominantly benign.

a Rounded to nearest integer. 
static nodes were associated with few solid nodes, some of which were microcalcified.

The incidence of metastasis was higher among the 37 PTC nodular cases with exclusively malignant US features (table 3 ) than among PTC cases with US features common to PTC and BTN, whether they were predominantly malignant or predominantly benign.

\section{Discussion}

The value of the US features of PTC as indicators of its malignancy is assessed in the current study with reference to the US findings in a group of BTN. In this study, US identification of the malignant nature of PTC was based on certain US features that were seen exclusively in PTC and not in BTN and were considered as indicators of PTC malignancy (table 1). Other studies in the literature on thyroid sonography have emphasized the importance of all these features as indicators of thyroid malignancy [3-5, 7-15].

It was also reasoned that since US features, particularly the subtle ones, are largely operator- as well as US-system-dependent, the US diagnosis of PTC malignancy based on the simultaneous presence of multiple exclusively malignant US features in any one case was considered as more certainly positive than that based on the presence of only a single feature. The presence of US evidence of direct and/or lymphatic extrathyroidal malignant spread was considered as the most positive indicator of malignancy [3-5]. Both these modes of spread can be detected at an earlier stage and with more certainty by real-time high-resolution US than by clinical evaluation $[16,17]$. According to the above-mentioned evaluation criteria, US presentation of the 39 PTC cases that were reviewed was categorized into four groups (table 2). In the first group of $29(74 \%)$ cases, the US identification of ma- lignancy was considered as certainly positive due to the presence of multiple exclusively malignant features. In the second group of 3 (8\%) cases, the US diagnosis of malignancy was less certain than the first group due to the presence of benign features together with the malignant features. In the third group $6(15 \%)$ US presentations were benign. In the fourth group, which is the least certain, US was negative for malignant features and diagnosis was made by histopathology as occult PTC.

On reviewing the literature, it was apparent that a cystic thyroid nodule with an endoluminal fixed projecting solid mural component is a sign of thyroid malignancy, particularly of PTC [4, 5]. Hatabu et al. [11] reported that during a review of US findings in 115 patients operated on for nodular thyroid lesions, all cystic thyroid nodules with a punctately calcified solid excrescence projecting from the cyst wall into its lumen ( 8 cases) were histopathologically proven to be cystic papillary carcinomas. They labeled this form of US presentation as 'calcific nodule within cyst sign', and considered it as a new and very specific sonographic sign for cystic PTC.

During our study, we examined a case of midline cervical mass clinically diagnosed as thyroglossal cyst. Sonographically the mass was cystic with a fixed punctately calcified solid nodule projecting from the cyst wall into its lumen [18]. The thyroid gland was located in its normal position and showed normal US features. A sonographic diagnosis of cystic papillary thyrogenic carcinoma of a thyroglossal duct remnant was suggested and later confirmed histopathologically. Fine needle aspiration biopsy (FNAB) of this lesion was performed twice; one was nonguided and was false-negative, while the other was US-guided and was positive. In such composite cystic lesions, nonguided FNAB often gives a relatively high false-negative rate. A false-negative fine needle aspiration cytology was re- 
ported by Hatabu et al. [11] in 38\% of the 8 cases of cystic PTC, and by Muller et al. [19] in $45 \%$ of the 11 cases in their studies. US guidance of FNAB [20-22] in such cases helps guide the needle into the solid endoluminal component.

While Hatabu et al. [11] indicated that calcification of the projecting nodule within the cystic thyroid lesion was seen in all cystic PTC, other authors [13-15, 19] described almost totally cystic as well as predominantly cystic PTC without mentioning the presence of calcification of the endocystic projecting solid components. However, in our study, 1 cystic BTN and 2 cystic PTC had similar projecting endoluminal solid mural nodules, but there were no detectable microcalcifications in both the 2 PTC cases as well as in the BTN case. Consequently, only those cystic thyroid nodules with punctate calcification of the endoluminal projecting solid components were considered as specifically diagnostic of the histotype of primary cystic PTC in our study.

In the current study, totally cystic metastatic lymph nodes as well as composite cystic nodes with microcalcified intraluminal solid components were seen in all PTC metastatic lymph nodes and associated with solid meta- static nodes in few cases. Only the cystic type metastatic lymph nodes were considered as PTC-specific. Accordingly, identification of the specific histotype of PTC was limited in this study to the cystic form of this tumor whether it was primary or metastatic in the lymph nodes. While the histotype of 5 cystic primary PTC (13\%) was directly identified, that of 11 solid and 1 occult primary PTC (31\%) was indirectly identified on the basis of having PTC-characteristic metastatic lymph nodes, i.e. collectively, the histotype of $44 \%$ of the 39 PTC reviewed was sonographically identified.

\section{Conclusion}

High-resolution real-time US was found to be a useful first line diagnostic modality of PTC and was reliable in differentiating benign from malignant thyroid nodules. It was reliable in identifying the histotype of PTC in cases with cystic metastasis or where the primary or the metastatic nodule is cystic with microcalcified projecting solid mural nodule. FNAB is to be resorted to, mainly in equivocal cases.

\section{References}

1 Leopold GR: Ultrasonography of superficially located structures. Radiol Clin North Am 1980;18:161173.

2 Butch RI, Simeone JF, Muller PR: Thyroid and parathyroid ultrasonography. Radiol Clin North Am 1985;23:57-71.

3 Bruneton JN: Ultrasonography of the Neck. Berlin, Springer, 1987, pp 22-48.

4 Solbiati L, Cioffi V, Ballerati E: Ultrasonography of the neck. Radiol Clin North Am 1992;30:941-954.

Sonographic Diagnosis of Papillary Thyroid Carcinoma
5 Solbiati L, Crose F, Crogrove D, Meire H, Dembury K: Thyroid and Parathyroid glands: Abdominal and General Ultrasound. London, Churchill Livingstone, 1994, vol 2, pp 661-680.

6 Al-Sayer HM, Bayliss AP, Krukowski ZH, Matheson NA: The limitations of ultrasound in thyroid swellings. J R Coll Surg Edinb 1986;31: 27-31.

7 Solbiati L, Ballarati E, Croff Y: Microcalcifications: A clue in the diagnosis of thyroid malignancies. Proc 76th RSNA, Chicago, 1990, p 140.
8 Kasatkin IUN, Ametov AS, Mitkov BB, Olshonskii VO, Voronetskii IB: Ultrasonic diagnosis of nodular lesions of the thyroid (abstract). Med Radiol (Mosk) 1989;34:14-19.

9 Brkljacic B, Cuk V, Tomic-Brzac H, Bence Zigman Z, Delic Brkljacic D, Drinkovic I: Ultrasound evaluation of benign and malignant nodules in echographically multinodular thyroids. J Clin Ultrasound 1994;22: 71-76.

10 Fuji Y, Wakausgi K, Yamada T: A study of ultrasonic diagnostic criteria for thyroid nodules. Proc 57th SUM, Takamatsu, 1990, p 433. 
11 Hatabu H, Kassagi K, Yammamoto K, Lida Y, Misaki T, Hidoka A, Shibata T, Shoji K, Highuchi K: Cystic papillary carcinoma of the thyroid: A new sonographic sign. Clin Radiol 1991;43:121-124.

12 Lu C, Chang C, Hsiao L, Kuo MS Ultrasonographic findings of papillary thyroid carcinoma and relations to pathologic changes. J Formos Med Assoc 1994;93:933-938.

13 de los Santos ET, Keyhani-Rofagha S, Cunningham JJ, Mazzaferri EL: Cystic thyroid nodules: The dilemma of malignant lesions. Arch Intern Med 1990;150:1422-1427.

14 Simeone JF, Daniels GH, Mueller PR, Mazzaferri EL: High-resolution real time ultrasonography of the thyroid. Radiology 1981;144:745-751.
15 Conrad C: Ultrasonography of the thyroid. Eur J Radiol 1985;5:218220.

16 Gritzman N, Grasl MCH, Helmer $\mathrm{M}$, Steiner E: Invasion of carotid artery and jugular vein by lymph node metastasis: Detection with sonography. Am J Roentgenol 1990; 154:411-414.

17 McConahey WM, Hay ID, Woolner LB, Van Heerden JA, Taylor WF: Papillary thyroid cancer treated at the Mayo Clinic, 1946 through 1970: Initial manifestations, pathologic findings, therapy and outcome. Mayo Clin Proc 1986;61(12):978996.

18 Al-Tammami MY, Al-Khawari H, Al-Manfouhi H: Primary cystic papillary thyroglossal duct carcinoma: Diagnosis by ultrasonography. J Kuwait Med Assoc 1997;29:76-78.
19 Muller N, Cooperberg PL, Suen KC, Thorson SG: Needle aspiration biopsy in cystic papillary carcinoma of the thyroid. Am J Roentgenol 1985;144:251-253.

20 Crepinko I, Krezevie H, Ohad A, Bence Zigman Z: Advantages of ultrasound guided FNA-needle aspiration thyroid biopsy. Period Biol 1989;91:469.

21 Walfish PG, Itazani E, Sleautridge HTG: Combined ultrasound and needle aspiration cytology in the assessment and management of hypofunctioning thyroid nodule. Am Intern Med 1997;87:270.

22 Sutton RT, Reading CC, Charboneae S: US-guided biopsy of neck mass in postoperative management of patients with thyroid cancer. Radiology 1988;168:769-772. 